\title{
Current Status of the Treatment for Sacral Chordomas and its Future Trends
}

\author{
Akira Nakamura, Kanji Mori*, Kazuya Nishizawa and Shinji Imai
}

Department of Orthopaedic Surgery, Shiga University of Medical Science, Tsukinowa-cho, Seta, Otsu, Shiga, 520-2192, Japan

\begin{abstract}
Chordomas are rare slow-growing, low to intermediate-grade malignant neoplasms (less than 5\% of all primary bone neoplasms); however they sometimes metastasise to distant organs. The 10 -year overall survival rate is relatively low. The sacrococcygeal region is one of the most common sites. Intensive surgery is the first line for the treatment, since chordomas are resistant to chemotherapy. In turn, radiotherapy presents marginal effect. It has been reported that surgical margins govern local recurrence and survival. However, sacral chordomas represent a therapeutic challenge as a large number of sacral chordomas are often very large at the time of diagnosis and may comprise adjacent vital organs. Sacrectomy includes four surgical approaches; i.e., a combined sequential anterior and posterior approach, a combined simultaneous anterior and posterior approach, a posterior approach alone and combined extended ilioinguinal and posterior approaches. Because of its large invasion, various postoperative complications were considered. Bladder, bowel and sexual dysfunction and wound complications were major and important complications. The efficacy of adjuvant therapy for the treatment of sacral chordoma is under debate. Chemotherapy has not significant benefit to local control as well as overall survival in patients with chordomas. Standard dose of radiotherapy is not effective for chordomas, either. Some authors described that Hadron-based therapy has several advantages compared with conventional photon-based therapy. Recently some authors described efficacy of new molecular-targeting agents. The infrequency of this disease has prevented to establish the optimal treatment. In this review, we summarized accumulating knowledge of the treatment for sacral chordomas and discuss future trends.
\end{abstract}

Keywords: Bladder and bowel function, chordoma, molecular-targeting agents, radiation, sacrum, surgical resection, wound complication.

\section{INTRODUCTION}

Chordomas are rare slow-growing, low to intermediate-grade malignant neoplasms, which are thought to arise from cellular remnants of the notochord [1]. Chordomas represent less than $5 \%$ of all primary bone tumors. They can arise from bone in the skull base and anywhere along the spine; however the most common site is the sacrococcygeal region $(40 \%-50 \%)$ and the base of the skull $(35 \%-40 \%)$ followed by the vertebral bodies $(15 \%-20 \%)[2,3]$.

Despite low to intermediate-grade tumor, chordomas metastasize to distant organs such as the lungs, bone, soft tissues, lymph nodes, liver and skin in up to $43 \%$ of patients $[4,5]$. The 10 -year overall survival rate ranges from $30 \%$ to $65 \%$ [6-12].

Intensive surgery remains the first line for the treatment, since chordomas are resistant to chemotherapy. In turn, radiotherapy shows marginal effect $[6,7,9,13,14]$. It has been reported that surgical margins govern both local

*Address correspondence to these authors at the Department of Orthopaedic Surgery, Shiga University of Medical Science, Tsukinowa-cho, Seta, Otsu, Shiga, 520-2192, Japan; Tel: +81-77-548-2252; Fax: +81-77-548-2254;

E-mail: kanchi@belle.shiga-med.ac.jp recurrence and survival $[7,8]$. Indeed, recent literatures reported that the rate of local recurrence ranging between $0 \%$ and $60 \%$ for wide margins, between $31 \%$ and $71 \%$ for marginal margins, and between $67 \%$ and $100 \%$ for intralesional resection margins [11, 15-20].

Sacral chordomas represent a therapeutic challenge as a large number of sacral chordomas are often very large at the time of diagnosis (Fig. 1) and may comprise adjacent vital organs. The large sizes, anatomical complexity of the pelvis, intimate relation with neurovascular structures, make it extremely difficult to extirpate the lesion with adequate margins [8].

In this review, we summarized accumulating knowledge of the treatment for sacral chordomas.

\section{SURGICAL RESECTION}

In the 1970s, the concept of wide en block surgical resection for the treatment of sacral tumors was advocated by Stener and Gunterberg [21]. Since then, en block excision, i.e., sacrectomy has remained a first line in the surgical management of sacral chordoma. Owing to the development of more vigorous surgery which enables wider surgical margins, local control of the lesions has significantly improved 


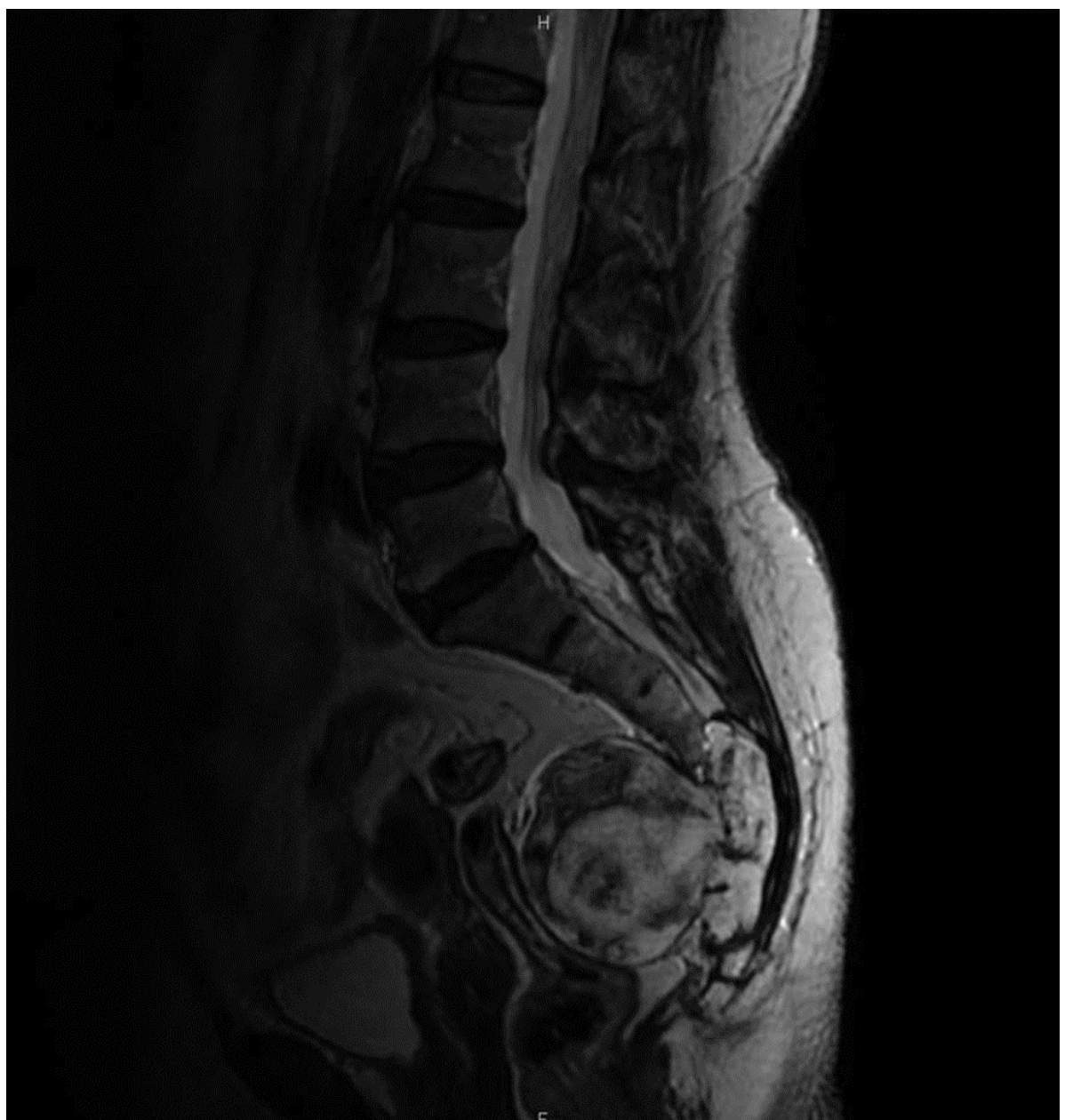

Fig. (1). Magnetic resonance imaging of 66 years old female patient with sacral chordoma at the time of diagnosis revealed a large soft tissue mass emanating from the sacrum.

in chordomas [22]. Sacrectomy includes four surgical approaches; i.e., a combined sequential anterior and posterior approach, a combined simultaneous anterior and posterior approach, a posterior approach alone and combined extended ilioinguinal and posterior approaches [23-25].

A less invasive, posterior alone approach may be enough for the resection of smaller, distal lesions [18, 24, 26, 27]. Contrary, for proximal chordomas and/or for chordomas infiltrating the mesorectum, a combined approach allows us to confirm the proximal end of the lesion in the pelvis and facilitates en bloc removal of the ano-rectum with the sacral lesion. Accordingly, some authors considered that the extension of the lesion above S3 needs a combined approach [7, $15,18]$.

Some authors suggested that the extension of the lesions into adjacent soft tissue was a significant risk factor for inadequate surgical margins $[13,15]$. The surgical strategies are needed to discuss carefully at a multidisciplinary sarcoma tumor team to achieve adequate surgical margins at the initial surgery.

The efficacy of adjuvant therapy for the treatment of sacral chordoma is under debate. Chemotherapy (cyclophosphamide, doxorubicin, dacarbazine, vincristine, cisplatin, methotrexate) does not have significant benefit to local control as well as overall survival in patients with chordomas. Radiotherapy is another option of adjuvant therapy in other malignant tumors; however standard dose of radiotherapy $(\leq 60 \mathrm{~Gy})$ is not effective for chordomas [4, 28, 29]. However, recent advances in radiation technology and treatment show possible favorable effect of radiotherapy (see Radiotherapy section).

Schwab et al., reported the capability of cryosurgery for the treatment of chordomas in adjuvant setting [17]. Cryosurgery was first indicated to both benign and malignant tumors by Cahan [30, 31]. Marcove promoted the indication of its use in bone tumors [32]. Subsequently, several authors used cryosurgery for the treatment of sacral tumors including chordomas in adjuvant setting [33, 34]. Schwab et al., reported that the patients who had wide contaminated margins treated with cryosurgery in adjuvant setting did not show a higher recurrence rate or lower survival rate compared to those who received wide resection [17]. Further studies are needed to confirm the capability of cryosurgery as a local adjuvant therapy for the treatment of chordomas.

\section{POSTOPERATIVE COMPLICATIONS}

Bladder, bowel and sexual dysfunction, motor deficits, lymphatic complications, pelvic hematomas, cerebrospinal 
Table 1. Association of most cranial preserved root level and bowel and bladder function [6, 24, 35, 38, 39].

\begin{tabular}{|c|c|c|c|}
\hline & & \multicolumn{2}{|c|}{ Percentage of Patients who have Minimal or no Problem of Bowel and Bladder Function } \\
\hline Most Cranial Preserved Root & Bowel Function & Bladder Function \\
\hline \hline Bil S3 & $75-100$ & $20-77.8$ \\
\hline Bil S2 & $25-77.8$ & $0-5.3$ \\
\hline Bil S1 & $0-20$ & $60 *$ \\
\hline Uni S3 & $62.5-67$ & $50 *$ \\
\hline Uni S2 & & $25 *$ & 500 \\
\hline Bil: bilateral Uni: unilateral * Only one author described. & & \\
\hline
\end{tabular}

fluid fistulae, deep-vein thrombosis and wound complications were previously reported common postoperative complications sacral chordomas in the literature [7, 17, 22, 3537].

Wound complications are one of the major complications, which are found around half of the patients $[8,17,36$, 37]. The majorities of them were managed with local control care as an outpatient setting, however some patients were required operative management such as operative debridement and musculocutaneous flaps [17]. Several authors advocated to use omental flap [8], transverse rectus abdominis musculocutaneous flap [7, 17]. Chen et al. [37] found that low albumin $(<3.0 \mathrm{~g} / \mathrm{dL})$, longer operating times ( $>6$ hours $)$ and previous surgery were statistically significant risk factors for wound infection after sacral tumor surgeries.

Bladder and bowel dysfunction is another major concern. Percentage of patients who had minimal or no problem of bowel and bladder function after sacrifice of sacral nerve roots was summarized according to the previous reports [6, $24,35,38,39]$. If bilateral S3 nerve roots were preserved (bilateral S4 nerve roots were sacrificed), many patients have almost normal bowel and bladder function (75-100\% patient: bowel function, $69-100 \%$ patient: bladder function). When bilateral S2 nerve roots were intact (bilateral S3 nerve roots were sacrificed), bowel function of $25-77.8 \%$ patient was maintained and bladder function of $20-77.8 \%$ patient was maintained. If bilateral S2 nerve roots were sacrificed (bilateral S1 nerve roots were preserved), many patients have bowel and bladder problem (0-20\% patients' bowel function was maintained and $0-5.3 \%$ patients' bladder function was maintained). If unilateral S3 nerve root was spared, 62.5$67 \%$ patients have normal bowel function, and $60 \%$ patients have normal bladder function. If unilateral S2 nerve root was preserved, $25 \%$ patients' bowel function was maintained, and $50 \%$ patients' bladder function was maintained (Table 1). Intriguingly, Schwab et al., sound an alarm concerning the pudendal nerves. Larger sacral tumors can comprise or approximate the pudendal nerve. Sacrifices of bilateral pudendal nerves lose any bowel, bladder or sexual function even if all the sacral roots are preserved [17].

\section{RADIOTHERAPY}

The use of radiation therapy as a primary or adjuvant treatment for chordomas is controversial, because effective dose to eradicate chordomas is much higher than the tolerance dose of the spinal cord and rectum. Treatment with conventional radiotherapy at dose of 40-60 Gy has yielded only 10-40\% 5-year local control [4, 28, 29]. Recent developments of radiation technology and treatment have allowed more planned targeting of neoplasms with higher doses of radiation.

High-dose protons or charged particles, i.e., carbon ions, helium, or neon can deliver higher dose of radiation to the target, which improve radiobiological effect with minimum side effect to the adjacent normal tissues [40-42]. Hadronbased therapy has several advantages compared with conventional photon-based therapy. Accumulating results suggested its efficacy for the treatment of chordoma. Indeed, hadron therapy in skull base, cervical spine and sacrococcygeal chordomas achieved 50-60\% 5-year local control [43, 44].

\section{SUMMARY AND FUTURE TRENDS}

Despite vigorous, careful surgical management and strict surveillance protocols, a considerable percentage of the patients will develop local recurrence and late onset metastasis [45]. Recent advance of molecular researches open the door for the treatment of chordomas. Overexpression of platelet-derived growth factor receptor (PDGFR) A, PDGFRB and KIT receptors has confirmed in chordomas. These findings can contribute to develop new moleculartargeting agents [46]. Indeed, preliminary reports have shown favorable effect of imatinib, a tyrosine-kinase inhibitor with specificity for the kinase domain of PDGFR and KIT receptors in both symptomatic and radiological levels in patients with advanced disease [47, 48].

Clinical trials targeting other agents, i.e., epidermal growth factor receptor (EGFR) (cetuximab, gefitinib and erlotinib) [49, 50] and signal transducer and activation of transcription 3 (STAT3) [51, 52] in the treatment of chordomas were ongoing, we are looking forward to their results. 
The infrequency of this disease has prevented to establish the optimal treatment. We believe that accumulated experiences in the treatment of sacral chordomas might well contribute to establish its optimal treatment.

\section{CONFLICT OF INTEREST}

The authors confirm that this article content has no conflict of interest.

\section{ACKNOWLEDGEMENTS}

Declared none

\section{REFERENCES}

[1] Vujovic S, Henderson S, Presneau N, et al. Brachyury, a crucial regulator of notochordal development, is a novel biomarker for chordomas. J Pathol 2006; 209: 157-65.

[2] Dahlin DC, Maccarty CS. Chordoma. Cancer 1952; 5: 1170-8.

[3] Healey JH, Lane JM. Chordoma: A critical review of diagnosis and treatment. Orthop Clin North Am 1989 ; 20: 417-26.

[4] Catton C, O'Sullivan B, Bell R, et al. Chordoma: Long-term follow-up after radical photon irradiation. Radiother Oncol 1996; 41: 67-72.

[5] Sopta J, Tulic G, Mijucic V, Mamontov P, Mandic N. Solitary lymph node metastasis without local recurrence of primary chordoma. Eur Spine J 2009; 18(Suppl 2): 191-5.

[6] Baratti D, Gronchi A, Pennacchioli E, et al. Chordoma: natural history and results in 28 patients treated at a single institution. Ann Surg Oncol 2003; 10: 291-6.

[7] Fuchs B, Dickey ID, Yaszemski MJ, Inwards CY, Sim FH. Operative management of sacral chordoma. J Bone Joint Surg Am 2005; 87: 2211-6.

[8] Hulen CA, Temple HT, Fox WP, et al. Oncologic and functional outcome following sacrectomy for sacral chordoma. J Bone Joint Surg Am 2006; 88: 1532-9.

[9] Higinbotham NL, Phillips RF, Farr HW, Hustu HO. Chordoma. Thirty-five-year study at Memorial Hospital. Cancer 1967; 20: 1841-50.

[10] Chambers PW, Schwinn CP. Chordoma. A clinicopathologic study of metastasis. Am J Clin Pathol 1979; 72: 765-76.

[11] Moojen WA, Vleggeert-Lankamp CL, Krol AD, Dijkstra SP. Longterm results: adjuvant radiotherapy in en bloc resection of sacrococcygeal chordoma is advisable. Spine (Phila Pa 1976) 2011; 36: E656-61.

[12] Ferraresi V, Nuzzo C, Zoccali C, et al. Chordoma: clinical characteristics, management and prognosis of a case series of 25 patients. BMC Cancer 2010; 10: 22.

[13] Chen KW, Yang HL, Lu J, Liu JY, Chen XQ. Prognostic factors of sacral chordoma after surgical therapy: a study of 36 patients. Spinal Cord 2010; 48: 166-71.

[14] Cheng EY, Ozerdemoglu RA, Transfeldt EE, Thompson RC Jr. Lumbosacral chordoma. Prognostic factors and treatment. Spine (Phila Pa 1976) 1999; 24: 1639-45.

[15] Hanna SA, Aston WJ, Briggs TW, Cannon SR, Saifuddin A. Sacral chordoma: can local recurrence after sacrectomy be predicted? Clin Orthop Relat Res 2008; 466: 2217-23.

[16] Ahmed AR. Safety margins in resection of sacral chordoma: analysis of 18 patients. Arch Orthop Trauma Surg 2009; 129: 483-7.

[17] Schwab JH, Healey JH, Rose P, Casas-Ganem J, Boland PJ. The surgical management of sacral chordomas. Spine (Phila Pa 1976) 2009; 34: 2700-4.

[18] Ruggieri P, Angelini A, Ussia G, Montalti M, Mercuri M. Surgical margins and local control in resection of sacral chordomas. Clin Orthop Relat Res 2010; 468: 2939-47.

[19] Asavamongkolkul A, Waikakul S. Wide resection of sacral chordoma via a posterior approach. Int Orthop 2012; 36: 607-12.

[20] Garofalo F, Christoforidis D, di Summa PG, et al. The unresolved case of sacral chordoma: from misdiagnosis to challenging surgery and medical therapy resistance. Ann Coloproctol 2014; 30: 122-31.
[21] Stener B, Gunterberg B. High amputation of the sacrum for extirpation of tumors. Principles and technique. Spine (Phila $\mathrm{Pa} 1976$ ) 1978; 3: 351-66.

[22] Hsieh PC, Xu R, Sciubba DM, et al. Long-term clinical outcomes following en bloc resections for sacral chordomas and chondrosarcomas: a series of twenty consecutive patients. Spine (Phila Pa 1976) 2009; 34: 2233-9.

[23] Gennari L, Azzarelli A, Quagliuolo V. A posterior approach for the excision of sacral chordoma. J Bone Joint Surg Br 1987; 69: 565-8.

[24] Samson IR, Springfield DS, Suit HD, Mankin HJ. Operative treatment of sacrococcygeal chordoma. A review of twenty-one cases. J Bone Joint Surg Am 1993; 75: 1476-84.

[25] Simpson AH, Porter A, Davis A, et al. Cephalad sacral resection with a combined extended ilioinguinal and posterior approach. J Bone Joint Surg Am 1995; 77: 405-11.

[26] Atalar H, Selek H, Yildiz Y, Sağlik Y. Management of sacrococcygeal chordomas. Int Orthop 2006 ; 30: 514-8.

[27] Devin C, Chong PY, Holt GE, et al. Level-adjusted perioperative risk of sacral amputations. J Surg Oncol 2006; 94: 203-11.

[28] Forsyth PA, Cascino TL, Shaw EG, et al. Intracranial chordomas: a clinicopathological and prognostic study of 51 cases. J Neurosurg 1993; 78: 741-7.

[29] Cummings BJ, Hodson DI, Bush RS. Chordoma: the results of megavoltage radiation therapy. Int J Radiat Oncol Biol Phys 1983; 9: 633-42.

[30] Cahan WG. Cryosurgery of the Uterus: description of technique and potential application. Am J Obstet Gynecol 1964; 88: 410-4.

[31] Cahan WG. Cryosurgery of malignant and benign tumors. Fed Proc 1965 ; 24: S241-8.

[32] Marcove RC, Miller TR, Cahan WC. The treatment of primary and metastaticbone tumors by repetitive freezing. Bull N Y Acad Med 1968; 44: 532-44.

[33] de Vries J, Oldhoff J, Hadders HN. Cryosurgical treatment of sacrococcygeal chordoma. Report of four cases. Cancer 1986; 58: 2348-54.

[34] Kollender Y, Meller I, Bickels J, et al. Role of adjuvant cryosurgery in intralesional treatment of sacral tumors. Cancer 2003; 97 : 2830-8.

[35] Guo Y, Palmer JL, Shen L, et al. Bowel and bladder continence, wound healing, and functional outcomes in patients who underwent sacrectomy. J Neurosurg Spine 2005; 3: 106-10.

[36] Sciubba DM, Nelson C, Gok B, et al. Evaluation of factors associated with postoperative infection following sacral tumor resection. J Neurosurg Spine 2008; 9: 593-9.

[37] Chen KW, Yang HL, Lu J, et al. Risk factors for postoperative wound infections of sacral chordoma after surgical excision. J Spinal Disord Tech 2011; 24: 230-4.

[38] Todd LT Jr, Yaszemski MJ, Currier BL, et al. Bowel and bladder function after major sacral resection. Clin Orthop Relat Res 2002; 397: 36-9.

[39] Bergh P, Kindblom LG, Gunterberg B, et al. Prognostic factors in chordoma of the sacrum and mobile spine: a study of 39 patients. Cancer 2000; 88: 2122-34.

[40] Suit HD, Goitein M, Munzenrider J, et al. Definitive radiation therapy for chordoma and chondrosarcoma of base of skull and cervical spine. J Neurosurg 1982; 56: 377-85.

[41] Austin-Seymour M, Munzenrider JE, Goitein M, et al. Progress in low-LET heavy particle therapy: intracranial and paracranial tumors and uveal melanomas. Radiat Res Suppl 1985; 8: S219-26.

[42] Austin-Seymour M, Munzenrider J, Linggood R, et al. Fractionated proton radiation therapy of cranial and intracranial tumors. Am J Clin Oncol 1990; 13: 327-30.

[43] Austin-Seymour M, Munzenrider J, Goitein M, et al. Fractionated proton radiation therapy of chordoma and low-grade chondrosarcoma of the base of the skull. J Neurosurg 1989; 70: 13-7.

[44] Noël G, Feuvret L, Calugaru V, et al. Chordomas of the base of the skull and upper cervical spine. One hundred patients irradiated by a $3 \mathrm{D}$ conformal technique combining photon and proton beams. Acta Oncol 2005; 44: 700-8.

[45] Walcott BP, Nahed BV, Mohyeldin A, et al. Chordoma: current concepts, management, and future directions. Lancet Oncol 2012; 13: e69-76.

[46] Negri T, Casieri P, Miselli F, et al. Evidence for PDGFRA, PDGFRB and KIT deregulation in an NSCLC patient. Br J Cancer 2007; 96: 180-1. 
[47] Casali PG, Messina A. Imatinib mesylate in chordoma. Cancer 2004; 101: 2086-97.

[48] Stacchiotti S, Marrari A. Tamborini E. Response to imatinib plus sirolimus in advanced chordoma. Ann Oncol 2009; 20: 1886-94.

[49] Hof H, Welzel T. Effectiveness of cetuximab/gefitinib in the therapy of a chordoma. Onkologie 2006; 29: 572-4.
[50] Singhal N, Kotasek D. Response to erlotinib in a patient with treatment refractory chordoma. Anticancer Drugs 2009; 20: 953-5.

[51] Yang C, Schwab JH. A novel target for treatment of chordoma: STAT3. Mol Cancer Ther 2009; 8: 2597-605.

[52] Yang C, Hornicek FJ. Blockage of Stat3 with CDDO-Me inhibits tumor cell growth in chordoma. Spine 2010; 35: 1668-75.

Received: November 13, 2014

Revised: March 13, 2015

Accepted: March 18, 2015

(C) Nakamura et al.; Licensee Bentham Open.

This is an open access article licensed under the terms of the Creative Commons Attribution Non-Commercial License (http://creativecommons.org/licenses/bync/3.0/), which permits unrestricted, non-commercial use, distribution and reproduction in any medium, provided the work is properly cited. 